patients were divided into two groups according to whether there was a $\% 50$ reduction in VAS

Results: The study was completed with 68 patients and 114 hands. While in group 1, in which VAS reduction was less than $\% 50$, there were 38 hands; in group 2 , in which VAS reduction wan more than $\% 50$, there were 76 hands. There were no differences improvement of symptom severity, nerve conduction studies parameters, M-CSA at the level of radio-ulnar joint between groups. Improvement of functional capacitiy and descrease of M-CSA at the level of pisiform bone and hook of hamate were significantly better in group $2(p<0.05)$.

Conclusions: After conservative treatment, while M-CSA was consistent with clinical findings, this consistency has not been observed with nerve conduction studies. M-CSA may be used to follow-up after receiving conservative treatment in patient with CTS.

Disclosure of Interest: None declared

DOI: 10.1136/annrheumdis-2018-eular.5656

\section{AB1073 THE EFFECTS OF LYMPHEDEMA SEVERITY ON DYNAMIC SCAPULAR CONTROL}

E. Baran, T.I. Yıldız, C. Orhan, E. Üzelpasacı, S. Özgül, I. Düzgün, T. Akbayrak. Department of Physiotherapy and Rehabilitation, Hacettepe University Faculty of Health Sciences, Ankara, Turkey

Background: Women with mastectomy are reported to have altered dynamic scapular control compared to the asymptomatic healthy individuals. However, the effects of breast cancer related lymphedema (LE) on scapular control has not been fully understood yet. ${ }^{1,2}$

Objectives: The aim of this study was to determine the impact of LE severity on scapular kinematics in breast cancer patients with moderate LE, severe LE and without LE.

Methods: 67 women who have undergone radical or modified radical mastectomy as part of the breast cancer treatment were included in the study. The study was approved by the local ethics committee of the university and all participants provided written informed consent. Individual's demographic and medical characteristics were recorded. By volumetric measurement, women were divided into 3 groups. Between the affected and non-affected extremities; the non-LE group (group $1, \mathrm{n}=22$ ) had 0 and $200 \mathrm{cc}$ difference, the moderate LE group (group 2, $\mathrm{n}=18$ ) had 250-500cc difference, and the severe LE group (group3, $\mathrm{n}=27$ ) had a difference of $500 \mathrm{cc}$ or more. 3-D analysis of the scapula was performed during the bilateral upper extremity elevation in the scapular plane with the 3D Motion Monitor-Electromagnetic System. Scapular kinematics in the scapular plane were recorded at $30^{\circ}, 60^{\circ}$ and $90^{\circ}$ (during elevation and lowering phases) of the arm elevation in the affected side. Each measurement was repeated 3 times and the mean of 3 repetitions were recorded. Patient characteristics and scapular kinematics were analysed by Kruskal Wallis test and two-way repeated measures of ANOVA test, respectively.

Results: There was no significant difference between groups in terms of age (mean ages; group 1: 45.54 \pm 5.88 , group 2: $52.05 \pm 6.63$, group 3: $56.37 \pm 8.24$ years) $(\mathrm{p}=0.08)$. Regarding the Body Mass Index (BMI) (group 1: $25.57 \pm 2.92$, group 2: $25.95 \pm 2.35$, group 3: $28.93 \pm 1.02 \mathrm{~kg} / \mathrm{m}^{2}$ ), it was found that group $3 \mathrm{had}$ higher BMI scores than group 1 and $2(p<0.001)$. The duration of LE (group 2 : $22.38 \pm 23.1$, group $3: 42.29 \pm 31.85$ months) was higher in group 3 than the group 2 $(p=0.004)$. There were significant interactions for scapular upward rotation between groups $\left(F_{4.11,131.51}=3.09, p=0.015\right)$. It was observed that group 1 had higher scapular upward rotation at $60^{\circ}$ and $30^{\circ}$ of the lowering phase of the arm elevation trials than group $3(p=0.013, p=0.004)$. There was no significant interaction in terms of the scapular internal rotation $\left(F_{4.37,139.9}=0.59, p>0.05\right)$ and posterior tilt $\left(\left(\mathrm{F}_{5.05,161.8}=1.02, \mathrm{p}=0.4\right)\right.$ among groups during the arm elevation in scapular plane.

Conclusions: The results of this study revealed that scapular upward rotation could be reduced by LE severity. LE severity might also be associated with BMI and LE duration. Further studies comparing LE patients with healthy individuals are needed to better understand the effects of LE severity on scapular kinematics.

\section{REFERENCES:}

[1] Shamley D, Srinaganathan R, Oskrochi R, Lascurain-Aguirrebena I, Sugden E. Three-dimensional scapulothoracic motion following treatment for breast cancer. Breast cancer research and treatment. 2009;118(2):315-22.

[2] Crosbie J, Kilbreath SL, Dylke E, Refshauge KM, Nicholson LL, Beith JM, et al. Effects of mastectomy on shoulder and spinal kinematics during bilateral upper-limb movement. Physical therapy. 2010;90(5):679-92.

Disclosure of Interest: None declared

DOI: 10.1136/annrheumdis-2018-eular.5683

\section{$\mathrm{AB} 1074$ \\ IN DEGENERATIVE SPINE DISEASE REGULAR SHORT COURSES OF NSAIDS USE ARE ASSOCIATED WITH GREATER KIDNEY INJURY, COMPARED WITH CONTINUOUS NSAIDS INTAKE AND WITH ABSENCE OF NSAIDS TREATMENT}

1.Z. Gaydukova ${ }^{1}$, D. Bichurina ${ }^{2}$, A. Rebrov ${ }^{3} .{ }^{1}$ Therapy and Rheumatology, NorthWestern State Medical University n.a.ll Mechnicov, St Petersburg; ${ }^{2}$ Bolshaya Kazachiia, 112; ${ }^{3}$ Saratov State Medical University na VIRazumovskyy, Saratov, Russian Federation

Background: Nephrotoxicity in short-term or continuous NSAIDs administration is well-known problem of anti-inflammatory treatment. However, data about kidney injury in case of repeated short-term courses of NSAIDs treatment are limited. Objectives: of the present study was to evaluate the kidney functions in patients with degenerative spine disease (DSD), taking NSAIDs in repeated short courses compared with kidney function of patients with constant NSAIDs intake and to the healthy individuals.

Methods: The study included 137 patients, taking NSAIDs for DSD. 97 patients used NSAIDs in repeated short-term courses (3-5 courses per year, 7-14 days each course). 40 patients had continuous NSAIDs intake (5 and more days per week during the 1 year before the study). In the control group were involved healthy persons, did not treated with NSAIDs during the last year $(n=40)$. Controls were sex- and age-matched with the DSD patients. Glomerular filtration rate (GFR) was calculated using CKD-EPI calculator. Albumin, $\alpha 1$-microglobulin and creatinine levels of urea were measured; albumin/creatinine and $\alpha 1$-microglobulin/creatinine ratios were calculated.

Results: Kidney function in DSD patients with NSAIDs intake and in healthy controls are presented in table 1.

Abstract AB1074 - Table 1. Kidney function in patients with short-term and continuous NSAIDs use and in healthy controls

\begin{tabular}{lccc}
\hline $\begin{array}{l}\text { Kidney function } \\
\text { parameter }\end{array}$ & $\begin{array}{c}\text { NSAIDS short } \\
\text { courses, } \mathrm{n}=97\end{array}$ & $\begin{array}{c}\text { NSAIDs continuous } \\
\text { intake, } \mathrm{n}=40\end{array}$ & $\begin{array}{c}\text { Controls, } \\
\mathrm{n}=40\end{array}$ \\
\hline GFR, ml/min/1.73 m² & $77.5[68.0 ; 89.0]$ & $86[68.0 ; 92.2]$ & $82.5[70.8 ;$ \\
& & & $90]$ \\
Albumin/creatinine, $\mathrm{mg} / \mathrm{g}$ & $57.1[33.8 ; 82,4]^{*} \#$ & $32[21.0 ; 44.4]^{*}$ & $25.0[17.5 ;$ \\
& & & $32.9]$ \\
a1-microglobulin/ & $134.7[77.5 ; 197.7]^{*} \#$ & $66.0[41.0 ; 112.3]^{*}$ & $12.9[0.5 ;$ \\
creatinine, $\mathrm{mg} / \mathrm{g}$ & & & $18.1]$ \\
\hline
\end{tabular}

${ }^{*} p<0.000$ for the difference with controls; $\#-p<0.000$ for the difference with NSAIDs' continuous intake.

In patients with DSD and short NSAIDs' use a decrease in GFR of less than $90 \mathrm{ml} / \mathrm{min} / 1.73 \mathrm{~m}^{2}$ was evaluated in $61(62.9 \%)$ of cases, GFR less than $60 \mathrm{ml}$ $\mathrm{min} / 1.73 \mathrm{~m}^{2}$ was detected in $11(11.3 \%)$ patients. In patients with DSD and continuous NSAIDs use a decrease in GFR of less than $90 \mathrm{ml} / \mathrm{min} / 1.73 \mathrm{~m}^{2}$ was evaluated in $34(85 \%)$ of cases, GFR less than $60 \mathrm{ml} / \mathrm{min} / 1.73 \mathrm{~m}^{2}$ was detected in 2 $(12.5 \%)$ patients, $p<0.01$, compared with controls and $p \geq 0.05$ compared with short-term use. GFR less than $60 \mathrm{ml} / \mathrm{min} / 1.73 \mathrm{~m}^{2}$ was found in 11 (11.3\%) patients with DSD and short NSAIDs intake and in $0(0 \%)$ of healthy volunteers $(p=0.026)$. Albumin/creatinine ratio $\geq 30 \mathrm{mg} / \mathrm{g}$ was found in $74(76.3 \%)$ patients with DSD with short-term NSAIDs use, in 22 (55\%) patients with constant NSAIDs intake, and $9(22.5 \%)$ healthy individuals ( $<<0.01$ for all intergroup differences) An increased level of microglobulin/creatinine ratio was found in $66 \%$ patients with DSD (in $82.4 \%$ cases of short-term and in $25 \%$ of continuous NSAIDs use $\mathrm{p}<0.01)$ and in $3(7.5 \%)$ healthy individuals, $\mathrm{p}<0.0001$.

Conclusions: Decrease of the GFR less than $60 \mathrm{ml} / \mathrm{min} / 1.73 \mathrm{~m}^{2}$ and subclinical kidney injury in patients, treated with NSAIDs, was found frequently, than in healthy persons never treated with NSAIDs. The subclinical glomerular and tubular damage in patients with short-term courses of NSAIDs use exceeded glomerular and tubular changes in patients with constant NSAIDs use.

Disclosure of Interest: None declared

DOI: 10.1136/annrheumdis-2018-eular.5762

\section{AB1075 \\ RELATIONSHIP OF SERUM CHOLECALCIFEROL (VITAMIN D3) LEVEL WITH MUSCULOSKELETAL SYMPTOMS}

M.A. Razzaque ${ }^{1}$, G. Dewan ${ }^{2}$, R.S. biswas ${ }^{3}$, M.N. karim², I. sultan ${ }^{4}$, on behalf of research only. ${ }^{1}$ pharmacology; ${ }^{2}$ medicine, Rangamati Medical college; ${ }^{3}$ medicine, chittagong ma o shishu medical college; ${ }^{4}$ medicine, cmc, chittagong, Bangladesh

Background: Patients suffering from generalised aches and pains, not adequately responding to treatment are usually considered as fibromyalgia depression, chronic fatigue syndrome etc. But those patients need further 
evaluation and low vitamin $D$ is often the underlying cause. Both clinical and subclinical low level vitamin $\mathrm{D}$ is common. ${ }^{1}$

Objectives: To assess the relationship between musculoskeletal complaints and serum vitamin $\mathrm{D}_{3}$ (cholecalciferol) level.

Methods: This prospective cross-sectional descriptive study was conducted during July 2017 to December 2017 in Chittagong, Bangladesh. Patients with common musculoskeletal complaints were enrolled. Each patient was screened to exclude common possibilities. Serum cholecalciferol was measured for each patient. Race, occupation, skin complexion, body mass index, sunlight exposure, covering of body with clothing's and use of sunscreen were taken under consideration in final analysis. Visual analogue scale (VAS; $1-10$ ) was used to quantify all complaints. Correlation of serum cholecalciferol level with VAS score of individual complaints was analysed.

Results: A total of 110 patients (79 Female and 31 Male) were enrolled after screening 165. All of them were Bangladeshi of multi-ethnic Asian origin. Mean age was $46.5 \pm 12.8$ years. Their skin complexions were pale white to white skin $45.5 \%$, light brown $30 \%$, moderate brown $11.8 \%$ and dark brown $12.7 \%$. Most had (90.9\%; $n=100)$ inadequate sunlight exposure and $77.2 \%(n=61)$ women used Burkah (full covered dress). Mean vitamin $D_{3}$ level was $25.2 \pm 7.3 \mathrm{ng} / \mathrm{ml}$. Vitamin $D$ deficiency was (mean $17.3 \pm 2.8 \mathrm{ng} / \mathrm{ml}$ ) observed in $30(27.3 \%)$, insufficiency (mean $25.1 \pm 2.7 \mathrm{ng} / \mathrm{ml}$ ) in $62(56.4 \%$ ) and normal level (mean $34.8 \pm 4.4 \mathrm{ng} / \mathrm{ml}$ ) in $18(16.4 \%)$. After classifying Vitamin D level in relation to symptoms it was found that majority of patients ( $81.2 \%$ to $90.3 \%$; depending on complaints) had insufficient or deficient cholecalciferol level (table 1).

Abstract AB1075 - Table 1. Serum cholecalciferol status in different musculoskeletal complaints

\begin{tabular}{|c|c|c|c|c|c|c|}
\hline \multirow[t]{2}{*}{ Complaints Vit $D_{3}$} & \multicolumn{2}{|c|}{$\begin{array}{c}\text { Normal } \\
(\geq 30 \mathrm{ng} / \mathrm{ml})\end{array}$} & \multicolumn{2}{|c|}{$\begin{array}{c}\text { Insufficiency } \\
(20-<30 \text { ng/ml) }\end{array}$} & \multicolumn{2}{|c|}{$\begin{array}{r}\text { Deficiency } \\
(<20 \mathrm{ng} / \mathrm{ml})\end{array}$} \\
\hline & $\mathrm{n}$ & $\%$ & $\mathrm{n}$ & $\%$ & $\mathrm{n}$ & $\%$ \\
\hline Myalgia $(n=104 ; 94.5 \%)$ & 16 & 15.4 & 60 & 57.7 & 28 & 26.9 \\
\hline Muscle cramp ( $n=104 ; 94.5 \%)$ & 18 & 17.3 & 60 & 57.7 & 26 & 25.0 \\
\hline Generalised weakness ( $n=99 ; 90.0 \%)$ & 18 & 18.2 & 56 & 56.5 & 25 & 25.2 \\
\hline Difficulty in climbing stairs ( $n=89 ; 80.9 \%)$ & 14 & 15.7 & 50 & 56.2 & 25 & 28.1 \\
\hline Fatigue $(\mathrm{n}=87 ; 79.1 \%)$ & 13 & 8.1 & 51 & 58.6 & 23 & 26.4 \\
\hline Difficulty in squatting $(\mathrm{n}=84 ; 76.4 \%)$ & 9 & 10.7 & 49 & 58.3 & 26 & 30.9 \\
\hline Pain in weight bearing joints $(n=80 ; 72.7 \%)$ & 11 & 3.7 & 49 & 61.2 & 20 & 25.0 \\
\hline Bone pain $(n=73 ; 66.4 \%)$ & 8 & 10.9 & 43 & 58.9 & 22 & 30.1 \\
\hline
\end{tabular}

Significant negative correlation was found between the serum cholecalciferol level and VAS for difficulty in getting up from squatting position ( $r=-0.253, p=0.008)$ and positive correlation was found for muscle cramps $(r=0.220, p=0.021)$. Correlations with remaining symptoms were not statistically significant.

Conclusions: Vitamin D status directly and indirectly influences musculoskeletal health. Hypovitaminosis D should consider in every patient with muscle cramp.

\section{REFERENCE:}

[1] Jones AN, Hansen KE. Recognizing the musculoskeletal manifestations of vitamin D deficiency. J Musculoskelet Med. 2009; 26(10): 389 - 96.

Acknowledgements: Hafsa habiba, Rayhana Begum

Disclosure of Interest: M. A. Razzaque Consultant for: research, G. Dewan Consultant for: research, R. biswas Consultant for: research, M. karim Consultant for: research, I. sultan Consultant for: research

DOI: 10.1136/annrheumdis-2018-eular.6070

\section{AB1076 COMPLEX REGIONAL PAIN SYNDROME TYPE 1: WHICH TREATMENT?}

M. Sghir ${ }^{1}$, S. Salah ${ }^{2}$, A. Haj Salah ${ }^{1}$, W. Kessomtini ${ }^{1}$, Z. Ben Salah ${ }^{2} .{ }^{1}$ Rehabilitation department, University Hospital Tahar Sfar, Mahdia; ${ }^{2}$ Rehabilitation department, University Hospital Fattouma Bourguiba, Monastir, Tunisia

Background: The treatment of Complex Regional Pain Syndrome Type 1 (CRPS-I) is multidisciplinary. ${ }^{1}$ It aims to minimise symptoms, pain, preserve functional ability and professional activity. Unfortunately, therapeutic possibilities are still very limited and there is no Gold standard.

Objectives: The purpose of our work is to evaluate the efficiency of four therapeutic modalities in the management of CRPS-I.
Methods: Retrospective study of 60 patients ( 21 men and 39 women) treated for CRPS-I. Four groups were identified according to therapeutic modalities used: rehabilitation alone (16 patients), Calcitonin associated with rehabilitation (15 patients), Bisphosphonates (BP) (Sodium Risedronate, 1 tablet per week, over an average duration of 1 month) associated with rehabilitation ( 20 patients) and Calcitonin in combination with $\mathrm{BP}$ and rehabilitation ( 9 patients).

Results: The mean age of the patients was $51 \pm 16.5$ years. The average time of treatment was 2 months and the average duration of follow-ups was 7 months. Traumatic origin was found in $88.3 \%$ of cases. Distal radius fractures (DRF) were the most incriminated ( $40 \%$ of cases). The evolution was judged on pain reduc tion, vasomotor signs and on functional improvement.

For all etiologies combined, no statistically significant difference was found between the different groups $(\mathrm{p}=0.462)$.

For patients with a DRF, a favourable outcome was noted in the BP group associated with rehabilitation in $85.7 \%$ of cases while it was only $42.9 \%$ for rehabilitation alone.

Conclusions: Our study concludes that the different therapeutic modalities evaluated for the treatment of CRPS-I had an efficiency close to each other with a superiority of BP. Oral Sodium Risedronate could therefore be proposed as a treatment for CRPS-I without marketing authorisation (MA).

\section{REFERENCE:}

[1] Hernández-Porras BC, Plancarte-Sánchez R, Alarcón-Barrios S, SámanoGarcía M. Complex regional pain syndrome: A review. Cirugía y Cirujanos (English Edition). 1 juill 2017;85(4):366-74.

Disclosure of Interest: None declared

DOI: 10.1136/annrheumdis-2018-eular.7477

\section{AB1077 INVESTIGATION OF FRAILITY, MOBILITY AND DAILY LIFE ACTIVITY IN ELDERLY}

U.K. Sahin, A. Demircioglu, N. Kirdi. Physical Therapy and Rehabilitation, Hacettepe University, ANKARA, Turkey

Background: There are many factors that affect negatively mobility and daily life activity of older people. Fraility is one of these. frailty is a state of decline in physiologic reserve capacity and resiliency due to impairment in multiple physiological systems, thereby causing vulnerability to death and adverse health outcomes.

Objectives: The aim of this study was to analyse gender differences in frailty, mobility and daily life activity score.

Methods: The study included 173 women, 124 men total 197 persons aged 65 years and older. The demographic information including age, height and weight, the individuals marital status, educational state, chronic diseases were taken. Elderly Mobility Scale (EMS), Edmonton Frail Scale (EFS) and KATZ were used to evaluate mobility, fraility and daily life activities level, respectively. Individuals were divided into groups according to their gender.

Results: There was significant difference between women and men in EMS $(p=0.001)$, EFS $(p<0.001)$ and KATZ scores $(0.048)$. Fraility score were lower, mobility score and daily life activity score higher than women in men. In both men and women were found positively a relation between mobility and daily life activity $(p<0.001)$, were found negatively a relation between fraility and mobility, daily life activity $(\mathrm{p}<0.001)$.

Conclusions: It was seen that female gender affected mobility, fraility and daily life activity. It is important that Strategies for preventing or delaying the predispos ing factor of frailty need to address gender differences and determinants among women.

\section{REFERENCES :}

[1] Fried, L.P., Ferrucci, L., Darer, J., Williamson, J.D., \& Anderson, G. (2004). Untangling the concepts of disability, frailty, and co-morbidity: Implications for improved targeting and care. Journal of Gerontology, Series A: Biological Sciences and Medical Sciences, 59(3), 255-63.

[2] Alexandre, Tiago da S., et al. "Gender differences in the incidence and determinants of components of the fraility phenotype among older adults: findings from the SABE study." Journal of aging and health 30.2 (2018): 190-212.

Disclosure of Interest: None declared

DOI: 10.1136/annrheumdis-2018-eular.7029 